\title{
Examination of explants by electron microscopy and correlations with the biomechanical score of prosthetic restorations with implant support
}

\author{
Examinarea unor explanturi prin microscopie electronică şi corelaţii cu \\ scorul biomecanic al restaurărilor protetice cu sprijin implantar
}

\author{
Michael Vitzu' ${ }^{1}$ Alexandru Daniel Referendaru', Emilian Hutu' ${ }^{1}$ Oana Botoacă², \\ Raluca Monica Comăneanu², Violeta Hancu², Mihail Târcolea ${ }^{3}$ \\ ${ }^{1}$ Şcoala Doctorală Medicină Dentară, Bucureşti, România \\ Facultatea de Medicină Dentară, Universitatea „Titu Maiorescu“, Bucureşti, România \\ 3Şcoala Doctorală Ştiinţa şi Ingineria Materialelor, Universitatea Politehnica, Bucureşti, România
}

\begin{abstract}
Objectives. The objective of our study was to evaluate the bone-implant interface in 10 cases of failure of fixed implant-prosthetic treatment by electron microscopy and spectrophotometry, in correlation with the evolution of Renouard-Rangert biomechanical scoring.

Material and method. The study material was represented by 10 dental implants of 3 different morphological types (A, B , C), from the Biomat @ collection, Polytechnic University of Bucharest, which were examined under the Phenom ProX electron microscope. The studied samples had a file in which there was noted the biomechanical score Renouard-Rangert from the treatment planning phase, but also from the patient dispensary phase. The survival time of the analyzed samples at the level of the maxillary bones was 7-24 months.

Results. Following the examination at the electron microscope, the presence of an adherent neoformation bone tissue was detected on every implant, which covered each implant relatively uniform, with different degrees of mineralization depending on the type of implant, the duration of bone implantation and evolution of biomechanical scoring in red or yellow.

Discussions. The use in our study only of standard size implants is an important advantage over other studies using mini-implants or temporary implants. The cases in which the biomechanical scoring reached "red" showed a lower degree of mineralization, and those that reached "yellow" had a higher degree of mineralization. Among the cases with biomechanical soring "in yellow" were samples collected from the posterior maxillary region, generally considered a risk area in implantology.

Conclusions. In our study we found a correspondence between the modification of the Renouard-Rangert biomechanical scoring and the degree of mineralization of the bone deposited on the surface of the explants. Regardless of the evolution of biomechanical scoring, on all 10 analyzed samples we found a close contact between the neoformation tissue and the implanted devices, which indicates the high biocompatibility of the three types of implants. The relatively small number of samples analyzed is a limitation of our study. In the future, we recommend, in order to validate the results, to extend the study to a greater number of cases.
\end{abstract}

Keywords: dental implant, electron microscopy, spectrophotometry, biomechanical score

\section{REZUMAT}

Obiective. Obiectivul studiului nostru a fost evaluarea interfeţei os-implant în 10 cazuri de eşec al tratamentului implanto-protetic fix prin microscopie electronică şi spectrofotometrie, în corelaţie cu evoluţia scorului biomecanic Renouard-Rangert.

Material şi metodă. Materialul de studiu a fost reprezentat de 10 implanturi dentare de 3 tipuri morfologice diferite $(A, B, C)$, provenite din colecţia BiomatC, Universitatea Politehnica din București, care au fost examinate la microscopul electronic Phenom ProX. Probele studiate au avut o fişă în care era notat scorul biomecanic Renouard-Rangert din faza de planificare a tratamentului, dar şi din faza de dispensarizare a pacientului. Durata de supravieţuire a eşantioanelor analizate la nivelul oaselor maxilare a fost de 7-24 luni. 


\begin{abstract}
Rezultate. În urma examinării la microsopul electronic, pe fiecare implant a fost detectată prezenţa unui ţesut osos de neoformaţie aderent, care acoperea relativ uniform fiecare implant, cu grade de mineralizare diferite în funcţie de tipul de implant, de durata menţinerii implantului în os şi de virarea scorului biomecanic „în roşu“ sau „în galben“. Discuții. Utilizarea în studiul nostru doar a implanturilor de dimensiuni standard constituie un avantaj important, faţă de alte studii ce folosesc miniimplanturi sau implanturi cu caracter provizoriu. Cazurile în care scorul biomecanic a ajuns „în roşu“ au prezentat un grad mai redus de mineralizare, iar cele care au ajuns „în galben“ au avut un grad mai ridicat de mineralizare. Printre cazurile cu scor biomecanic „în galben“ au fost şi probe recoltate din regiunea posterioară maxilară, considerată în general o zonă de risc în implantologie.

Concluzii. În studiul nostru, am depistat o corespondenţă între modificarea scorului biomecanic Renouard-Rangert şi gradul de mineralizare a osului depus pe suprafaţa explantelor. Indiferent de evoluţia scorului biomecanic, pe toate cele 10 probe analizate am depistat un contact strâns între ţesutul de neoformaţie şi dispozitivele implantate, ceea ce indică biocompatibilitatea înaltă a celor 3 tipuri de implanturi. Numărul relativ redus de probe analizate constituie o limitare a studiului nostru. Recomandăm pe viitor, pentru validarea rezultatelor, extinderea studiului la un număr mai mare de cazuri.
\end{abstract}

Cuvinte cheie: implant dentar, microscopie electronică, spectrofotometrie, scor biomecanic

\section{INTRODUCERE}

Rata de eșec a terapiei implanto-protetice se situează, conform studiilor, între 3 şi $8 \%$, în corelaţie cu starea generală de sănătate a pacienţilor şi în funcție de designul implantului [1-4].

Datorită proprietăţilor mecanice şi chimice, dar şi capacităţii de osteointegrare şi biocompatibilităţii generale, aliajele de titan reprezintă în prezent materialele de elecţie utilizate pentru confecţionarea implanturilor dentare [5-7]. În ultimii ani, s-a pus accent pe tratamentul suprafeței implanturilor, dovedindu-se ştiinţific că rugozitatea suprafeței implantului accelerează integrarea osoasă [8-11]. În plus, au fost studiate depunerile pe suprafaţa implanturilor din aliaj de titan, cu intenția de a stimula oseointegrarea [12-14].

Renouard şi Rangert [15] au propus, pentru evaluarea prognosticului pe termen lung al restaurărilor implantoportate fixe, un scor biomecanic ce reprezintǎ însumarea unor note acordate pentru fiecare posibil factor de risc al unei proteze fixe cu sprijin implantar. Pentru fiecare restaurare implanto-protetică se poate stabili un scor iniţial, în faza de planificare a tratamentului, dar şi un scor final, pe baza analizei rezultatelor obţinute.

În prezentul studiu, am examinat prin microscopie electonică şi prin spectrofotometrie 10 cazuri de eşec al tratamentului implanto-protetic. Rezultatele obţinute au fost raportate la modificările de scor biomecanic [15] pentru fiecare caz. Un scor mai mic de 2 (,în verde“) nu relevă un factor de risc terapeutic, scorul între 2 şi 3 (,în galben“) presupune un risc mediu, iar un scor peste 3 (,,în roşu“) indică un risc crescut de eşec.

\section{MATERIAL ŞI METODĂ}

Am inclus în studiu 10 implanturi de 3 tipuri, cu diferite morfologii ale suprafețelor, din colecţia
Biomat $^{\mathscr{O}}$ - structură de cercetare din Universitatea Politehnica din Bucureşti.

Probele au fost investigate din punctul de vedere al compoziţie şi al morfologiei suprafeţei cu ajutorul microscopului electronic Phenom ProX (PhenomWorld, Olanda).

Probele studiate au avut o fişă în care exista notat scorul biomecanic Renouard-Rangert din faza de planificare a tratamentului, dar şi din faza de dispensarizare a pacientului. Durata de supravieţuire a eşantioanelor analizate la nivelul oaselor maxilare a fost de 7-24 luni.

Pe fiecare eşantion au fost selectate mai multe puncte în care s-a analizat prin spectrofotometrie compoziţia elementală, iar imaginile au fost achiziţionate la o mărire la 500x.

Acest studiu, fiind unul retrospectiv, nu a necesitat consimţământul scris al pacienţilor implicaţi.

\section{REZULTATE}

Probele 1-2-3 au conţinut implanturi de tip A, conic, cu suprafaţa prelucrată chimic (îmbogăţită cu fosfor, calciu şi oxigen) şi fizic (sablare cu particule de $\mathrm{Al}_{2} \mathrm{O}_{3}$ şi decapare acidă).

Prima probă a fost explantată din zona laterală maxilară a unei paciente de 69 ani. Pe respectivul implant era confecţionată o coroană amovibilă la care s-a produs fractura repetată a materialului fizionomic, ceea ce a impus îndepărtarea coroanei şi refacerea acesteia.

După fractura materialului ceramic a treia oară, la îndepărtarea coroanei s-a constatat apariţia mobilităţii implantului dentar. Fractura repetată a materialului fizionomic a dus la virarea ,în roşu“ a scorului biomecanic Renouard-Rangert.

Explantarea piesei s-a produs la 18 luni de la inserare şi după un an de la protezare, iar eşantionul 
prelevat a fost trimis la microsocopul electronic pentru examinare.

Proba 2 a fost explantată, de asemenea, din zona laterală maxilară, dar de la o pacientă de 52 ani. Respectivul implant nu a fost protezat, pentru că a prezentat de la început stabilitate primară redusă, cu scor biomecanic ,în galben“, care a virat ulterior ,în roşu“.

La descoperirea implantului la 7 luni de la inserare, s-a constatat că stabilitatea nu se îmbunătăţise, astfel încât s-a recomandat îndepărtarea implantului.
În urma examinării probelor 1 şi 2 , am constatat că pe suprafața implantului era depus un strat relativ uniform de ţesut de neoformaţie, care avea un grad redus de mineralizare.

Proba 3 a fost explantată din zona laterală maxilară a unui pacient de 63 ani. La controlul efectuat la 12 luni de la protezarea cu o coroană cimentată, respectiv 18 luni de la inserarea implantului, s-a constatat radiologic apariţia unei resorbţii oasoase periimplantare în pâlnie, ceea ce a schimbat „în roşu“ scorul biomecanic şi a indicat ablaţia coroanei şi a implantului.

\begin{tabular}{|r|l|l|l|r|r|}
\hline & $\begin{array}{l}\text { Element } \\
\text { Number }\end{array}$ & $\begin{array}{l}\text { Element } \\
\text { Symbol }\end{array}$ & $\begin{array}{l}\text { Element } \\
\text { Name }\end{array}$ & $\begin{array}{l}\text { Atomic } \\
\text { Conc. }\end{array}$ & $\begin{array}{l}\text { Weight } \\
\text { Conc. }\end{array}$ \\
\cline { 2 - 7 } & 8 & $\mathrm{O}$ & Oxygen & 45.31 & 42.07 \\
\cline { 2 - 7 } & 6 & $\mathrm{C}$ & Carbon & 43.56 & 30.36 \\
\cline { 2 - 7 } & 22 & $\mathrm{Ti}$ & Titanium & 7.47 & 20.76 \\
\cline { 2 - 7 } & 13 & $\mathrm{Al}$ & Aluminium & 1.24 & 1.94 \\
\cline { 2 - 7 } & 20 & $\mathrm{Ca}$ & Calcium & 0.81 & 1.88 \\
\hline \multirow{3}{*}{} & 23 & $\mathrm{~V}$ & Vanadium & 0.32 & 0.96 \\
\hline & 15 & $\mathrm{P}$ & Phosphorus & 0.51 & 0.91 \\
\hline & 11 & $\mathrm{Na}$ & Sodium & 0.51 & 0.68 \\
\hline & 14 & $\mathrm{Si}$ & Silicon & 0.22 & 0.36 \\
\hline & 16 & $\mathrm{~S}$ & Sulfur & 0.05 & 0.09 \\
\hline
\end{tabular}

A

\begin{tabular}{|c|c|c|c|c|c|}
\hline$x^{2}, 3 x$ & \begin{tabular}{|l|} 
Element \\
Number
\end{tabular} & $\begin{array}{l}\text { Element } \\
\text { Symbol }\end{array}$ & $\begin{array}{l}\text { Element } \\
\text { Name }\end{array}$ & $\begin{array}{l}\text { Atomic } \\
\text { Conc. }\end{array}$ & $\begin{array}{l}\text { Weight } \\
\text { Conc. }\end{array}$ \\
\hline & 8 & $\mathrm{O}$ & Oxygen & 44.48 & 48.94 \\
\hline & 6 & $\mathrm{C}$ & Carbon & 39.49 & 32.62 \\
\hline & 7 & $\mathrm{~N}$ & Nitrogen & 14.54 & 14.00 \\
\hline & 22 & $\mathrm{Ti}$ & Titanium & 0.81 & 2.66 \\
\hline & 20 & $\mathrm{Ca}$ & Calcium & 0.54 & 1.50 \\
\hline & 15 & $P$ & Phosphorus & 0.10 & 0.22 \\
\hline 81 & 11 & $\mathrm{Na}$ & Sodium & 0.04 & 0.06 \\
\hline Hegnas? & 13 & $\mathrm{Al}$ & Aluminium & 0.00 & 0.00 \\
\hline Kes: & 14 & $\mathrm{Si}$ & Silicon & 0.00 & 0.00 \\
\hline 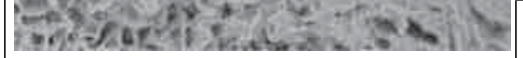 & 16 & $S$ & Sulfur & 0.00 & 0.00 \\
\hline
\end{tabular}

B

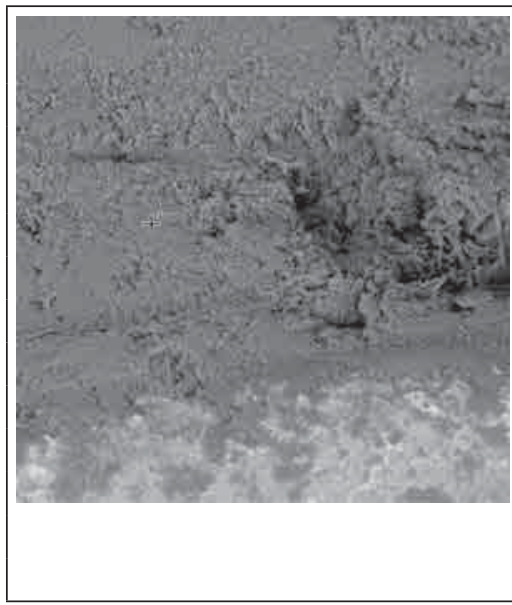

\begin{tabular}{|l|l|l|r|r|}
\hline $\begin{array}{l}\text { Element } \\
\text { Number }\end{array}$ & $\begin{array}{l}\text { Element } \\
\text { Symbol }\end{array}$ & $\begin{array}{l}\text { Element } \\
\text { Name }\end{array}$ & $\begin{array}{l}\text { Atomic } \\
\text { Conc. }\end{array}$ & $\begin{array}{l}\text { Weight } \\
\text { Conc. }\end{array}$ \\
\hline 6 & $\mathrm{C}$ & Carbon & 63.49 & 61.68 \\
\hline 7 & $\mathrm{~N}$ & Nitrogen & 17.80 & 20.17 \\
\hline 5 & $\mathrm{~B}$ & Boron & 14.64 & 12.80 \\
\hline 8 & $\mathrm{O}$ & Oxygen & 4.03 & 5.21 \\
\hline 16 & $\mathrm{~S}$ & Sulfur & 0.03 & 0.09 \\
\hline 15 & $\mathrm{P}$ & Phosphorus & 0.02 & 0.05 \\
\hline 11 & $\mathrm{Na}$ & Sodium & 0.00 & 0.00 \\
\hline 13 & $\mathrm{Al}$ & Aluminium & 0.00 & 0.00 \\
\hline 14 & $\mathrm{Si}$ & Silicon & 0.00 & 0.00 \\
\hline 20 & $\mathrm{Ca}$ & Calcium & 0.00 & 0.00 \\
\hline 22 & $\mathrm{Ti}$ & Titanium & 0.00 & 0.00 \\
\hline 23 & $\mathrm{~V}$ & Vanadium & 0.00 & 0.00 \\
\hline & $\mathrm{C}$ & & &
\end{tabular}

FIGURA 1. Aspectul probelor 1-3 (implanturi de tip A) la microscopul electronic şi analiza elementală prin spectrofotometrie 
Implantul a prezentat la examinarea prin microscopie electronică un strat neuniform de ţesut de neoformaţie, cu grad redus de mineralizare.

Probele 4-6 au conţinut implanturi de tip B, care au suprafaţa sablată şi ulterior gravată cu acizi carboxilici.

Proba 4 a fost explantată din zona laterală maxilară a unei paciente de 47 ani. La 18 luni de la încărcarea mecanică a implantului, pacienta a acuzat sensibilitate dureroasă în zonă şi sângerare la periaj, iar radiologic s-a depistat o resorbţie osoasă în pâlnie ce depăşea prima spiră a implantului. Producerea resorbţiei osoase a dus la virarea scorului biomecanic final ,în galben“. S-a recomandat ablaţia implantului şi proba prelevată a fost trimisă spre examinare la microscopul electronic.

Implantul a fost acoperit cu ţesut de neoformaţie bogat reprezentat, cu grad de mineralizare crescut.

Proba 5 a provenit de la o pacientă de 61 ani cu edentaţie laterală maxilară. La 2 ani după încărcarea

\begin{tabular}{|r|l|l|l|r|r|}
\hline 5 & $\begin{array}{l}\text { Element } \\
\text { Number }\end{array}$ & $\begin{array}{l}\text { Element } \\
\text { Symbol }\end{array}$ & $\begin{array}{l}\text { Element } \\
\text { Name }\end{array}$ & $\begin{array}{l}\text { Atomic } \\
\text { Conc. }\end{array}$ & $\begin{array}{l}\text { Weight } \\
\text { Conc. }\end{array}$ \\
\cline { 2 - 7 } & 8 & $\mathrm{O}$ & Oxygen & 43.65 & 35.33 \\
\hline & 20 & $\mathrm{Ca}$ & Calcium & 15.31 & 31.04 \\
\hline & 6 & $\mathrm{C}$ & Carbon & 23.80 & 14.46 \\
\hline & 15 & $\mathrm{P}$ & Phosphorus & 5.60 & 8.77 \\
\hline & 7 & $\mathrm{~N}$ & Nitrogen & 10.13 & 7.18 \\
\hline & 22 & $\mathrm{Ti}$ & Titanium & 1.09 & 2.63 \\
\hline & 11 & $\mathrm{Na}$ & Sodium & 0.24 & 0.28 \\
\hline & 14 & $\mathrm{Si}$ & Silicon & 0.06 & 0.09 \\
\hline & 23 & $\mathrm{~V}$ & Vanadium & 0.03 & 0.09 \\
\hline & 16 & $\mathrm{~S}$ & Sulfur & 0.06 & 0.09 \\
\hline & 13 & $\mathrm{Al}$ & Aluminium & 0.04 & 0.05 \\
\hline
\end{tabular}

A

\begin{tabular}{|r|l|l|l|l|r|}
\hline & $\begin{array}{l}\text { Element } \\
\text { Number }\end{array}$ & $\begin{array}{l}\text { Element } \\
\text { Symbol }\end{array}$ & $\begin{array}{l}\text { Element } \\
\text { Name }\end{array}$ & $\begin{array}{l}\text { Atomic } \\
\text { Conc. }\end{array}$ & $\begin{array}{l}\text { Weight } \\
\text { Conc. }\end{array}$ \\
\hline & 20 & $\mathrm{Ca}$ & Calcium & 14.39 & 29.76 \\
\hline & 8 & $\mathrm{O}$ & Oxygen & 34.21 & 28.25 \\
\hline & 7 & $\mathrm{~N}$ & Nitrogen & 37.60 & 27.18 \\
\hline & 22 & $\mathrm{Ti}$ & Titanium & 2.37 & 5.85 \\
\hline & 6 & $\mathrm{C}$ & Carbon & 9.34 & 5.79 \\
\hline & 15 & $\mathrm{P}$ & Phosphorus & 1.58 & 2.53 \\
\hline & 13 & $\mathrm{Al}$ & Aluminium & 0.27 & 0.37 \\
\hline & 11 & $\mathrm{Na}$ & Sodium & 0.25 & 0.29 \\
\hline & 23 & $\mathrm{~V}$ & Vanadium & 0.00 & 0.00 \\
\hline & 14 & $\mathrm{Si}$ & Silicon & 0.00 & 0.00 \\
\hline & 16 & $\mathrm{~S}$ & Sulfur & 0.00 & 0.00 \\
\hline
\end{tabular}

B

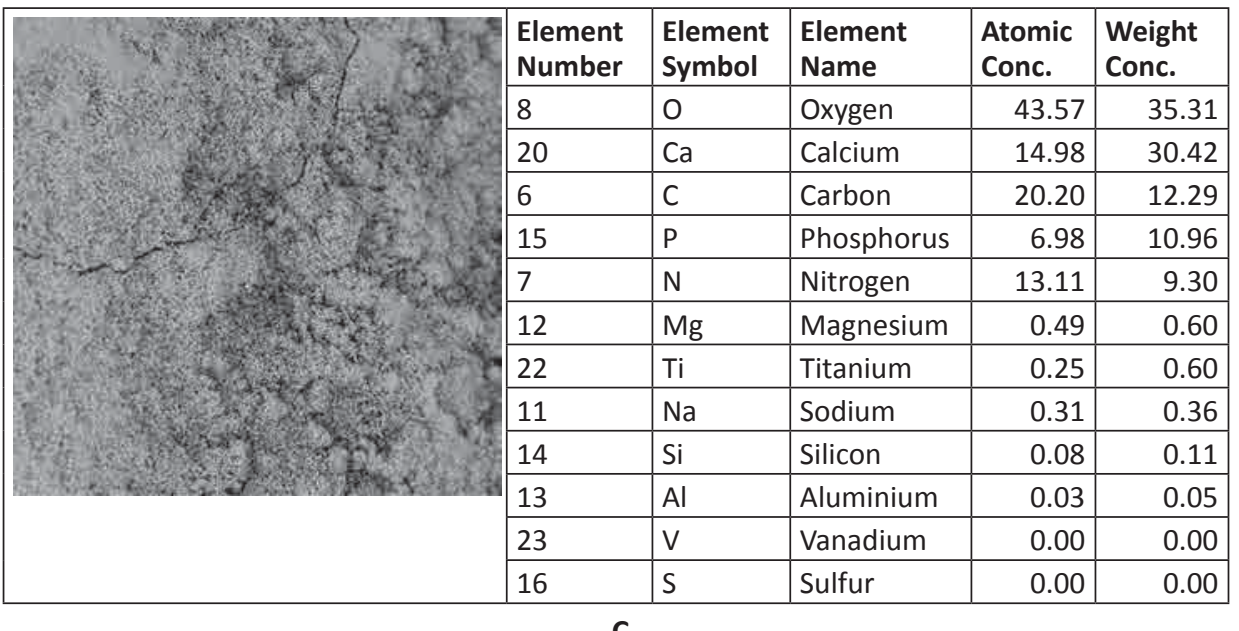

FIGURA 2. Aspectul probelor 4-6 (implanturi de tip B) la microscopul electronic şi analiza elementală prin spectrofotometrie 
protetică, clinic s-a constatat mobilitatea coroanei amovibile cu agregare implantară. La examenul radiologic recomandat pacientei am depistat o resorbţie osoasă în pâlnie ce depăşea prima spiră a implantului. Complicaţia terapeutică produsă a modificat scorul biomecanic ,în galben“ şi a dus la recomandarea de abaţie a restaurării şi a implantului.

La microscop, s-a evidenţiat acoperirea implantului cu ţesut de neoformaţie abundent, cu mineralizare crescută.

Proba 6 a provenit de la o pacientă în vârstă de 63 ani, ce prezenta în regiunea laterală maxilară o breşă edentată.

La acel nivel a fost inserat un implant pe care s-a confecţionat o coroană amovibilă, la care s-a slăbit în mod repetat şurubul de fixare. La aproximativ 1 an şi jumătate de la încărcarea ocluzală, pacienta a reclamat sângerare la periaj şi sensibilitate dureroasă în zonă. În urma examinării clinice, s-a evidenţiat mobilitatea crescută a ansamblului implant dentar-coroană, cu modificarea ,în galben" a scorului biomecanic, ceea ce a indicat ablaţia coroanei şi a implantului.

La examinarea prin microscopie electronică şi spectrofotometrie, am depistat acoperirea uniformă a implantului cu ţesut osos de neoformaţie, bogat mineralizat.

Probele 7-10 aparţin unor implanturi de tip C, care au suprafaţa iniţial sablată cu particule de mari dimensiuni, ce produc macrorugozităţi, acestea fiind apoi transformate în microrugozităţi, prin tratare acidă.

Proba 7 a fost recoltată din zona laterală maxilară a unui pacient de 58 ani. La 12 luni de la încărcarea ocluzală a implantului cu o restaurare protetică fixă cimentată, s-a constatat radiologic apariţia resorbţiei osoase în pâlnie, periimplantar. Complicaţia produsă a modificat scorul biomecanic ,în roşu“ şi a indicat ablaţia restaurării şi a implantului. La examinarea efectuată în cadrul centrului Biomat $(\mathrm{C}$, am decelat acoperirea implantului cu ţesut de neoformaţie, având o mineralizare foarte redusă.

Probele 8 şi 9 provin de la o pacientă de 53 ani, cu breşe edentate mandibulare, la nivelul cărora s-au inserat implanturi dentare pe care s-au confecţionat restaurări protetice fixe agregate prin înşurubare.

La 12 luni de la încărcarea ocluzală, s-a constatat că două dintre coroanele aplicate prezentau slăbirea repetată a şuruburilor de fixare, cu schimbarea ,în galben“ a scorului biomecanic.

S-a recomandat examinarea clinică a celor două implanturi după îndepărtarea lucrării protetice. S-a constatat mobilitatea implanturilor, ceea ce a impus ablaţia acestora. La microscopul electronic, s-a constatat acoperirea implanturilor cu ţesut osos de neoformaţie, având un grad de mineralizare crescut.

Proba 10 a fost recoltată din zona mandibulară laterală a unei paciente de 59 ani. La aproximativ 1 an după protezarea unuia dintre implanturile inserate la acest nivel, s-a produs decimentarea repetată a uneia dintre coroanele cu agregare pe implant, în asociere cu o mobilitate a implantului ce a evoluat în timp. Această complicaţie a schimbat scorul biomecanic ,în roşu“ şi a necesitat ablaţia coroanei şi a implantului.

La examinarea probei recoltate la microscopul electronic, s-a decelat prezenţa unui ţesut osos de neoformaţie bogat mineralizat, ce învelea relativ uniform implantul.

\section{DISCUȚII}

Din punct de vedere nanostructural, osul prezintă caracteristici constitutive mai reduse de $100 \mathrm{~nm}$, alcătuit din compuși organici (preponderent colagen), întăriţi de compuşi anorganici (hidroxiapatită) [16].

Este cunoscut faptul că evaluarea in vivo a osteointegrării se realizează cel mai bine prin analiza histomorfometrică şi histologică a ţesutului periimplantar recuperarat de pe suprafaţa unui implant ce a fost osteointegrat în osul nativ uman $[17,18]$. În practica curentă, se utilizează în acest scop cel mai frecvent miniimplanturile ortodontice sau implanturile temporare [17-20], dar în studiul nostru am utilizat implanturi pe care au funcţionat diverse perioade de timp restaurări protetice finite, dar şi-au pierdut stabilitatea.

Utilizarea în studiul nostru doar a implanturilor de dimensiuni standard reprezintă un avantaj, ca şi în alte studii $[16,21]$, care au analizat vindecarea osoasă în situaţii clinice reale.

În funcţie de textura suprafeţelor lor, de scorul biomecanic şi de durata de timp cât au fost inserate în os, implanturile erau acoperite cu țesut osos de diferite grosimi, aflat în diverse stadii de mineralizare. 


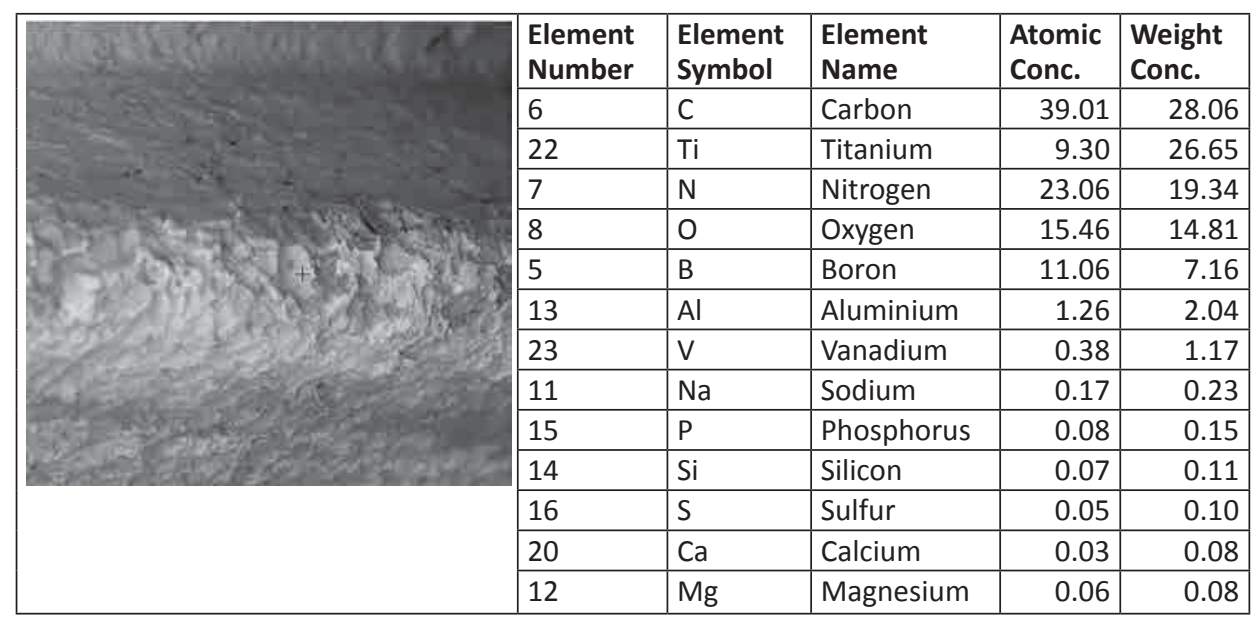

\section{A}

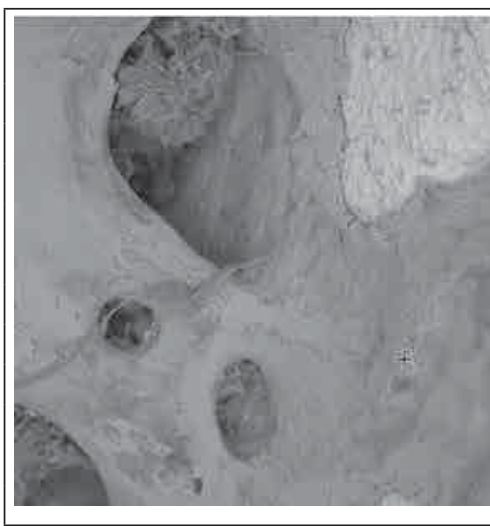

\begin{tabular}{|l|l|l|r|r|}
\hline $\begin{array}{l}\text { Element } \\
\text { Number }\end{array}$ & $\begin{array}{l}\text { Element } \\
\text { Symbol }\end{array}$ & $\begin{array}{l}\text { Element } \\
\text { Name }\end{array}$ & $\begin{array}{l}\text { Atomic } \\
\text { Conc. }\end{array}$ & $\begin{array}{l}\text { Weight } \\
\text { Conc. }\end{array}$ \\
\hline 20 & $\mathrm{Ca}$ & Calcium & 13.52 & 27.95 \\
\hline 8 & $\mathrm{O}$ & Oxygen & 30.25 & 24.96 \\
\hline 6 & $\mathrm{C}$ & Carbon & 27.66 & 17.14 \\
\hline 7 & $\mathrm{~N}$ & Nitrogen & 18.73 & 13.53 \\
\hline 15 & $\mathrm{P}$ & Phosphorus & 7.15 & 11.42 \\
\hline 22 & $\mathrm{Ti}$ & Titanium & 1.26 & 3.10 \\
\hline 11 & $\mathrm{Na}$ & Sodium & 0.66 & 0.78 \\
\hline 13 & $\mathrm{Al}$ & Aluminium & 0.37 & 0.52 \\
\hline 16 & $\mathrm{~S}$ & Sulfur & 0.16 & 0.26 \\
\hline 14 & $\mathrm{Si}$ & Silicon & 0.18 & 0.26 \\
\hline 12 & $\mathrm{Mg}$ & Magnesium & 0.05 & 0.07 \\
\hline
\end{tabular}

B

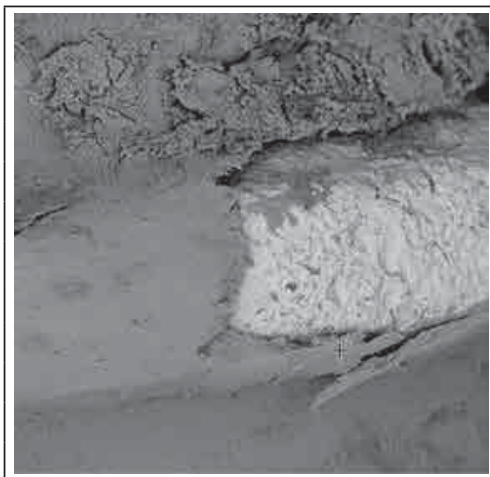

\section{\begin{tabular}{|l|l|l|l|l|} 
Element & Element & Element & Atomic & Weight \\
\hline
\end{tabular}}

\begin{tabular}{|l|l|l|l|l|} 
Number & Symbol & Name & Conc. & Conc. \\
\hline
\end{tabular}

\begin{tabular}{|l|l|l|r|r|}
\hline 20 & $\mathrm{Ca}$ & Calcium & 19.39 & 28.99 \\
\hline 8 & $\mathrm{O}$ & Oxygen & 30.80 & 18.38 \\
\hline 75 & $\mathrm{Re}$ & Rhenium & 2.49 & 17.33 \\
\hline 15 & $\mathrm{P}$ & Phosphorus & 11.85 & 13.69 \\
\hline 7 & $\mathrm{~N}$ & Nitrogen & 14.36 & 7.50 \\
\hline 6 & $\mathrm{C}$ & Carbon & 16.26 & 7.29 \\
\hline 22 & $\mathrm{Ti}$ & Titanium & 2.61 & 4.67 \\
\hline 11 & $\mathrm{Na}$ & Sodium & 0.91 & 0.78 \\
\hline 13 & $\mathrm{Al}$ & Aluminium & 0.54 & 0.54 \\
\hline 14 & $\mathrm{Si}$ & Silicon & 0.31 & 0.33 \\
\hline 16 & $\mathrm{~S}$ & Sulfur & 0.24 & 0.29 \\
\hline 12 & $\mathrm{Mg}$ & Magnesium & 0.23 & 0.21 \\
\hline & $\mathrm{C}$ & & &
\end{tabular}

C

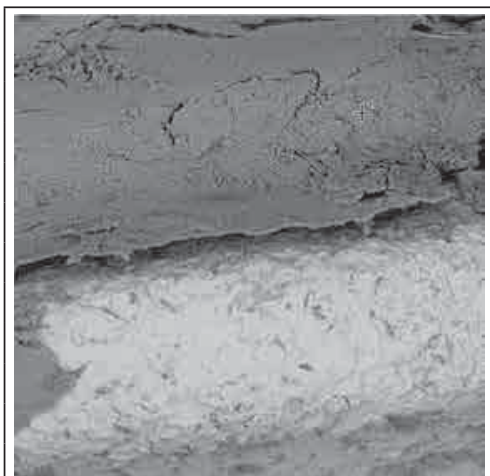

\begin{tabular}{|l|l|l|r|r|}
$\begin{array}{l}\text { Element } \\
\text { Number }\end{array}$ & $\begin{array}{l}\text { Element } \\
\text { Symbol }\end{array}$ & $\begin{array}{l}\text { Element } \\
\text { Name }\end{array}$ & $\begin{array}{l}\text { Atomic } \\
\text { Conc. }\end{array}$ & $\begin{array}{l}\text { Weight } \\
\text { Conc. }\end{array}$ \\
\hline 8 & $\mathrm{O}$ & Oxygen & 39.23 & 40.67 \\
\hline 6 & $\mathrm{C}$ & Carbon & 25.03 & 19.48 \\
\hline 7 & $\mathrm{~N}$ & Nitrogen & 19.23 & 17.45 \\
\hline 22 & $\mathrm{Ti}$ & Titanium & 2.54 & 7.86 \\
\hline 5 & $\mathrm{~B}$ & Boron & 10.70 & 7.50 \\
\hline 20 & $\mathrm{Ca}$ & Calcium & 1.38 & 3.58 \\
\hline 15 & $\mathrm{P}$ & Phosphorus & 1.00 & 2.01 \\
\hline 11 & $\mathrm{Na}$ & Sodium & 0.49 & 0.74 \\
\hline 13 & $\mathrm{Al}$ & Aluminium & 0.37 & 0.64 \\
\hline 14 & $\mathrm{Si}$ & Silicon & 0.02 & 0.04 \\
\hline 16 & $\mathrm{~S}$ & Sulfur & 0.01 & 0.02 \\
\hline 12 & $\mathrm{Mg}$ & Magnesium & 0.00 & 0.00 \\
\hline
\end{tabular}

FIGURA 3. Aspectul probelor 7-10 (implanturi de tip C) la microscopul electronic şi analiza elementală prin spectrofotometrie 
Cazurile în care scorul biomecanic a ajuns ,în roşu“ au prezentat un grad mai redus de mineralizare, iar cele care au ajuns ,în galben“ au avut un grad mai ridicat de mineralizare.

Printre cazurile cu scor biomecanic „în galben“, au fost şi probe recoltate din regiunea posterioară maxilară, considerată în general o zonă de risc în implantologie, ca urmare a densităţii osoase reduse de la acest nivel [22-27].

În toate probele examinate în prezentul studiu, contactul os-implant a fost strâns. Absenţa metodologiilor standardizate [28-30] pentru aprecierea creşterii osoase şi cuantificarea precisă a contactului os-implant fac necesară studierea în continuare a fenomenului de osteointegrare la nivel nanometric.

Conflict of interest: none declared

Financial support: none declared

\section{BIBLIOGRAFIE}

1. Tran D, Gay I, Diaz-Rodriguez J et al. Survival of dental implants placed in grafted and nongrafted bone: a retrospective study in a university setting. International Journal of Oral \& Maxillofacial Implants. 2016;31(2):310-317.

2. Lemos CAA, Alves MLF, Okamoto R et al. Short dental implants versus standard dental implants placed in the posterior jaws: a systematic review and meta-analysis. Journal of Dentistry. 2016;47:8-17.

3. Han HJ, Kim S, Han DH. Multifactorial evaluation of implant failure: a 19-year retrospective study. International Journal of Oral \& Maxillofacial Implants. 2014;29(2):303-310.

4. Sun HL, Huang C, Wu YR et al. Failure rates of short ( $\leq 10 \mathrm{~mm})$ dental implants and factors influencing their failure: a systematic review. International Journal of Oral \& Maxillofacial Implants. 2011;26(4):816-825.

5. Carlsson L, Rostlund T, Albrektsson T et al. Osseointegration of titanium implants. Acta Orthopaedica Scandinavica. 1986; 57(4):285-289.

6. Oldani C, Dominguez A. Titanium as a Biomaterial for Implants. In: Fokter S (ed.). Recent Advances in Arthroplasty. London: InTech Open, 2012.

7. Geetha M, Singh AK, Asokamani R et al. Ti based biomaterials, the ultimate choice for orthopaedic implants - a review. Progress in Materials Science. 2009;54(3):397-425.

8. Lee BEJ, Ho S, Mestres $\mathrm{G}$ et al. Dual-topography electrical discharge machining of titanium to improve biocompatibility. Surface and Coatings Technology. 2016;296:149-156.

9. Shah FA, Wang $X$, Thomsen $P$ et al. High-resolution visualization of the osteocyte lacuno-canalicular network juxtaposed to the surface of nanotextured titanium implants in human. ACS Biomaterials Science \& Engineering. 2015;1(5):305-313.

10. Palmquist A, Emanuelsson L, Brãnemark R et al. Biomechanical, histological and ultrastructural analyses of laser micro- and nano-structured titanium implant after 6 months in rabbit. Journal of Biomedical Materials Research Part B: Applied Biomaterials. 2011;97B(2):289-298.

11. Brånemark $R$, Emanuelsson $L$, Palmquist $A$ et al. Bone response to laser-induced micro- and nano-size titanium surface features. Nanomedicine: Nanotechnology, Biology and Medicine. 2011;7(2):220-227.

\section{CONCLUZII}

În studiul nostru, am depistat o corespondenţă între modificarea scorului biomecanic RenouardRangert şi gradul de mineralizare a osului depus pe suprafaţa explantelor. Indiferent de evoluţia scorului biomecanic, pe toate cele 10 probe analizate am depistat un contact strâns între ţesutul de neoformaţie şi dispozitivele implantate, ceea ce indică biocompatibilitatea înaltă a celor 3 tipuri de implanturi.

Numărul relativ redus de probe analizate constituie o limitare a studiului nostru. Recomandăm pe viitor, pentru validarea rezultatelor, extinderea studiului la un număr mai crescut de cazuri.

\section{Notă}

Toţi autorii au avut contribuţie egală la publicarea acestui material.

12. Grandfield K, Pujari S, Ott M et al. Effect of calcium and strontium on mesoporous titania coatings for implant applications. Journal of Biomaterials and Nanobiotechnology. 2013;4(2):107-113.

13. Sul YT, Jönsson J, Yoon GS et al. Resonance frequency measurements in vivo and related surface properties of magnesiumincorporated, micropatterned and magnesium-incorporated TiUnite $\AA$, Osseotite $®, S L A ®$ and TiOblast $₫$ implants. Clinical Oral Implants Research. 2009;20(10):1146-1155.

14. Poulos NM, Rodriguez NA, Lee $\mathrm{J}$ et al. Evaluation of a novel calcium phosphate-coated titanium porous oxide implant surface: a study in rabbits. International Journal of Oral \& Maxillofacial Implants. 2011;26(4):731-738.

15. Renouard F, Rangert B. Risk Factors in Implant Dentistry Quintessence Publishing 1999;29-38,39-66.

16. Mangano F, Raspanti M, Maghaireh H, Mangano C. Scanning Electron Microscope (SEM) Evaluation of the Interface between a Nanostructured Calcium-Incorporated Dental Implant Surface and the Human Bone. Materials (Basel). 2017 Dec 17;10(12):1438.

17. Mangano FG, Pires, JT, Shibli JA et al. Early Bone Response to Dual Acid-Etched and Machined Dental Implants Placed in the Posterior Maxilla: A Histologic and Histomorphometric Human Study. Implant Dent. 2017;26:24-29.

18. Kaluđerović MR, Schreckenbach JP, Graf HL. Titanium dental implant surfaces obtained by anodic spark deposition - From the past to the future. Mater Sci Eng C Mater Biol Appl. 2016 Dec 1;69:1429-41.

19. Mangano FG, lezzi G, Shibli JA, Pires JT, Luongo G, Piattelli A, Mangano $C$. Early bone formation around immediately loaded implants with nanostructured calcium-incorporated and machined surface: a randomized, controlled histologic and histomorphometric study in the human posterior maxilla. Clin Oral Investig. 2017 Nov;21(8):2603-2611.

20. Mangano C, Shibli JA, Pires JT, Luongo G, Piattelli A, lezzi G. Early Bone Formation around Immediately Loaded Transitional Implants Inserted in the Human Posterior Maxilla: The Effects of Fixture Design and Surface. Biomed Res Int. 2017;2017:4152506.

21. Comăneanu RM, Barbu HM, Coman $\mathrm{C}$ et al. Correlations between cyto-histopathological tissue changes at the dental implant interface and the degree of surface processing. RJME. 2014;55(2):335-341. 
22. Ghoul WE, Chidiac JJ. Prosthetic requirements for immediate implant loading: a review. J Prosthodont. 2012 Feb;21(2):141-54.

23. De Bruyn H, Raes S, Ostman PO, Cosyn J. Immediate loading in partially and completely edentulous jaws: a review of the literature with clinical guidelines. Periodontol 2000. 2014 Oct;66(1):153-87.

24. Duyck J, Vandamme K. The effect of loading on peri-implant bone: a critical review of the literature. J Oral Rehabil. 2014 Oct; 41(10):783-94.

25. Akoğlan M, Tatli U, Kurtoğlu C, Salimov F, Kürkçü M. Effects of different loading protocols on the secondary stability and periimplant bone density of the single implants in the posterior maxilla. Clin Implant Dent Relat Res. 2017 Aug;19(4):624-631.

26. Lioubavina-Hack N, Lang NP, Karring T. Significance of primary stability for osseointegration of dental implants. Clin Oral Implants Res. 2006 Jun;17(3):244-50.

27. Bosshardt DD, Chappuis V, Buser D. Osseointegration of titanium, titanium alloy and zirconia dental implants: current knowledge and open questions. Periodontol 2000. 2017 Feb;73(1):22-40.
28. Gehrke SA, Maté Sánchez de Val JE, Fernández Domínguez M, de Aza Moya PN, Gómez Moreno G, Calvo Guirado JL. Effects on the osseointegration of titanium implants incorporating calciummagnesium: a resonance frequency and histomorphometric analysis in rabbit tibia. Clin Oral Implants Res. 2018 Jul;29(7):785-791.

29. Park YS, Yi KY, Lee IS, Han CH, Jung YC. The effects of ion beam-assisted deposition of hydroxyapatite on the grit-blasted surface of endosseous implants in rabbit tibiae. Int J Oral Maxillofac Implants. 2005 Jan-Feb;20(1):31-8.

30. Marin C, Granato R, Suzuki M, Gil JN, Piattelli A, Coelho PG. Removal torque and histomorphometric evaluation of bioceramic grit-blasted/acid-etched and dual acid-etched implant surfaces: an experimental study in dogs. J Periodontol. 2008 Oct;79(10):1942-9. 